\title{
ASSESSING THE CORPORATE SOCIAL RESPONSIBILITY REPORTS BASED ON COMMUNICATION INDICATORS: AN ANP APROACH.
}

\author{
Tomás Gómez-Navarro* \\ Departamento de Proyectos de Ingeniería \\ Universitat Politècnica de València. Valencia. Spain \\ E-mail: tgomez@dpi.upv.es \\ Amparo Baviera-Puig \\ Departamento de Economía y Ciencias Sociales \\ Universitat Politècnica de València. Valencia. Spain \\ E-mail: ambapui@upv.es \\ Gabriel García-Martínez \\ Departamento de Economía y Ciencias Sociales \\ Universitat Politècnica de València. Valencia. Spain \\ E-mail: gagarmar@esp.upv.es
}

\begin{abstract}
CSR reports are intended to communicate the organization's CSR performance to stakeholders. Currently, CSR reports mainly follow well designed guidelines like the Global Reporting Initiative (GRI). However, various authors claim CSR reports are becoming more a publicity tool than a communication tool. To help assessing the communication performance of CSR reports, an assessment procedure is proposed based on ANP. ANP allows designing a communication index to rank CSR reports, taken as the alternatives, according to a set of communication indicators, taken as the criteria. In the proposed network, communication criteria were, among others: Relevance, Communication technique, Accuracy, Easiness to find particular data, Layout, etc. Criteria were arranged in four clusters namely: Quality, Reliability, Comprehension and Presentation. In order to test the procedure a set of comparable CSR reports were selected. The assessment model based on ANP and the assessment judgments were carried out by a panel of experts including an expert on communication theory, an expert on environmental NGOs' demands and an expert on consumers' demands. The case studies showed significant differences among the alternatives (the reports), allowing to establish four levels of communication performance: Excellent, Good, Fair and Poor. Logically, the assessment procedure not only allowed ranking the reports but also determining weaknesses and opportunities to improve the communication performance of each CSR report.
\end{abstract}

Keywords: Analytic Network Process (ANP), CSR Reports, Communication Quality

\section{Introduction}

There are many definitions of Corporate Social Responsibility (CSR). The most frequently used is the one offered by the Commission of the European Communities (COM, 2001) who defines CSR as a concept whereby companies integrate social and environmental concerns in their business operations and in their interaction with their stakeholders on a voluntary basis. This definition includes 5 dimensions: voluntariness, stakeholder, social, environmental and economic. Stakeholders are groups or individuals

\footnotetext{
${ }^{*}$ Corresponding author
} 
who affect or are affected by the activity aimed at achieving the company objectives (COM, 2001). The term stakeholder is used in contraposition to stockholders or shareholders.

Companies' CSR can be reflected in their CSR or Sustainability reports. These reports are used as an accountability and communication tool with the stakeholders and society. The Global Reporting Initiative (GRI) is a non-profit organization that promotes economic, environmental and social sustainability. GRI provides all companies and organizations with a comprehensive sustainability reporting framework that is widely used around the world.

However, many authors criticize that these reports are used as an advertizing tool instead of a communication tool (Du et al. 2010) or (Fassin 2008). In this research, we analyze the GRI reports of all large companies in the Spanish energy sector. The aim of this paper is to present a methodology for assessing and ranking the CSR reports based on communication criteria and the ANP method. To the knowledge of the authors, no other research has applied ANP to assessing the communication quality of CSR reports.

\section{Communication and CSR reports.}

\subsection{CSR reports as communication tools}

The CSR communication involves not only a change in the role of the company within the communication process but also a change in its objectives (Sanfey \& Hastie 1998). In the communication process in CSR, the company can not only deliver messages and content but also must be able to establish receiver channels for dialogue with its stakeholders in a common context, with the aim of capturing their expectations and needs (Fassin 2008). The CSR strategy in a company is based on its ability to capture and integrate those expectations and business management needs. Thus, communication becomes a mainstay of the business strategy (Sutantoputra, 2008).

Communicating CSR allows stakeholders to evaluate the various activities conducted by the company, beyond the required legal information, taking as reference values and corporate culture, the environment and its positioning against competitors, facilitating a more complete, close and emotional analysis.

\section{Methodology}

\subsection{Analytic Network Process (ANP)}

Details on the Analytic Network Process (ANP) can be found in Saaty (2001), however, the main steps are summarized here for completeness.

(i) Pairwise comparisons on the elements and relative weight estimation

The determination of relative weights in ANP is based on the pairwise comparison of the elements in each level. These pairwise comparisons are conducted with respect to their relative importance towards their control criterion based on the principle of AHP and measured using Saaty's 1-to-9 scale. The score of 'aij' in the pairwise comparison matrix represents the relative importance of the element on row (i) over the element on column (j), i.e., aij=wi/wj where 'wi' is the weight of the element (i). With respect to any criterion, pairwise comparisons are performed in two levels, i.e. the element level and the cluster level comparison. If there are $\mathrm{n}$ elements to be compared, the comparison matrix $\mathrm{A}$ is defined as (Eq. 1):

$$
\mathbf{A}=\left\langle\begin{array}{cccc}
\boldsymbol{w}_{1} / \boldsymbol{w}_{1} & \boldsymbol{w}_{1} / \boldsymbol{w}_{2} & \ldots & \boldsymbol{w}_{1} / \boldsymbol{w}_{n} \\
\boldsymbol{w}_{2} / \boldsymbol{w}_{1} & \boldsymbol{w}_{2} / \boldsymbol{w}_{2} & \ldots & \boldsymbol{w}_{2} / \boldsymbol{w}_{n} \\
\boldsymbol{w}_{n} / \boldsymbol{w}_{1} & \boldsymbol{w}_{n} / \boldsymbol{w}_{2} & \ldots & \boldsymbol{w}_{n} / \boldsymbol{w}_{n}
\end{array}\right\rangle=\left[\begin{array}{cccc}
1 & a_{12} & \ldots & a_{1 n} \\
a_{21} & 1 & \ldots & a_{2 n} \\
\ldots & \ldots & \ldots & \ldots \\
a_{n 1} & a_{n 2} & \ldots & 1
\end{array}\right]
$$




\section{T. Gómez-Navarro, A. Baviera-Puig, G. García-Martínez/Corporate social responsibility reports based on communication}

After all pairwise comparisons are completed the priority weight vector ' $w$ ' is computed as the unique solution of (Eq. 2)

$$
\mathrm{A} \times \mathrm{w}=\lambda \max \cdot \mathrm{w}(2)
$$

where ' $\lambda \max$ ' is the largest eigenvalue of matrix ' $A$ ' and ' $w$ ' is its eigenvector.

(ii) Construction of the original supermatrix (unweighted supermatrix)

The resulting relative importance weights (eigenvectors) in pairwise comparison matrices are placed within a supermatrix that represents the interrelationships of all elements in the system.

(iii) Constructing the weighted supermatrix

The following step consists of the weighting of the blocks of the unweighted supermatrix, by the corresponding priorities of the clusters, so that it can be column stochastic (weighted supermatrix).

(iv) Calculation of the global priority weights

Raising the weighted supermatrix to limiting powers until the weights converge and remain stable the limit supermatrix will be obtained. In this matrix, the elements of each column represent the final weights of the different elements considered. In order to endow the results with a higher value, it is advisable to have several experts involved in solving the problem of prioritization.

\subsection{Research procedure}

The modeling methodology followed in the study was divided into three phases: problem analysis, synthesis and evaluation (see Figure 1). The study was developed jointly by the research team, who played the role of ANP facilitators, one expert in communication and CSR reports and two representatives of the main stakeholders: Users and environmental NGOs. The communication expert was asked to act as a decision maker (DM) as well, that is to say, she participated in the whole procedure to help the authors assessing and discussing it.

As the aim of the modeling is assessing CSR reports as communication tools, the research compares the different interpretations of the criteria when ranking a catalogue of CSR reports of energy companies. The methodology, therefore, allows finding what the criteria for a good communication are, the discrepancies between the assessment of experts and stakeholders, and the communication quality of a particular set of CSR reports. Comparability among CSR reports was defined according to the organization's economic activity, its size, the publication date, the organization's scope covered by the report, the region, etc. This way the research focuses mainly on the communication features as the companies have similar target stakeholders, communication demands, or CSR concerns

\subsection{Communication criteria}

According to the literature review and the communication expert's suggestions the assessment criteria are:

\section{CLUSTER 1: COMPREHENSION OF THE DATA}

Criterion 1. Communication technique: It includes the narrative information besides bar graphs or data tables. According to Sanfey \& Hastie (1998) and Gibbs et al. (1996) stakeholders understand better narrative information than the same information in bar graphs or data tables. Moreover, Du et al. (2010) propose the inclusion of cause-effect relationships as they help to a better comprehension of the facts, the data or the intentions. Finally, Jewett and Hibbard (1996) argue the advantages of avoiding to use exclusively quantitative concepts or aggregations when explaining quality data as "understanding quantitative concepts and aggregations is a significant barrier for consumer's comprehension of quality data". 


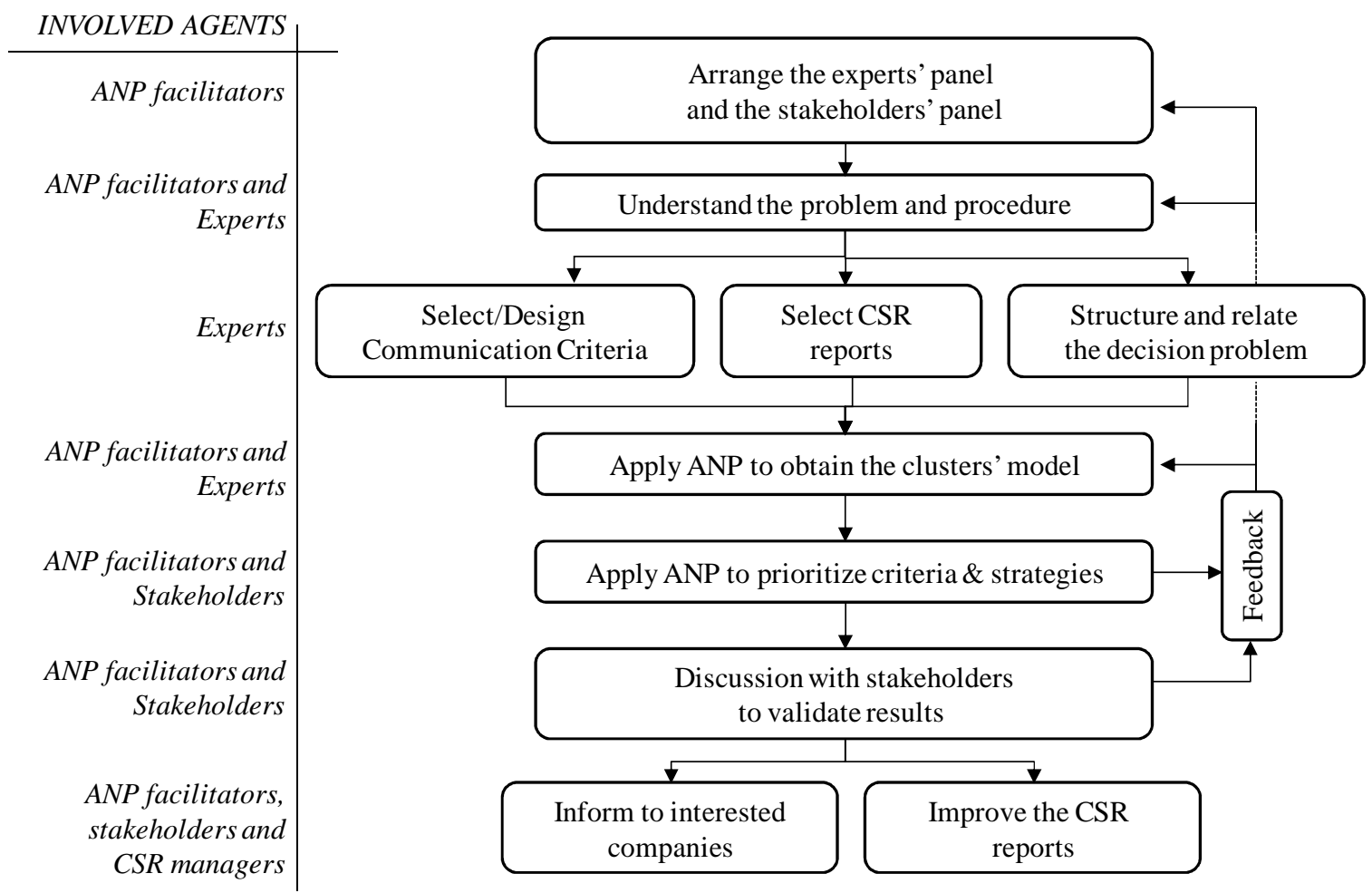

Figure 1. Research methodology.

Criterion 2. Comparability: It includes providing comparative data. The findings from the experiments of Hibbard et al. (2002) show evaluable displays of comparative data influence the degree to which information is actually weighted and used in choice. Also Knox et al. (2005) and Du et al (2010) argue the importance of the comparisons with competence and the periodicity and opportunity of the report.

Criterion 3. Clarity and simplicity: Several authors remark good communication relies on the use of natural language, i.e. the language, terms and meanings of respondents, avoiding jargon or technical language (Zeller, 1987). They add aids and abets make the report more accessible, including summaries or highlighted text (Coupland, 2006). For this, it is demanded syntactic simplicity, phrase structure simplicity and shunning inappropriate usage of third person and passive voice (Graesser et al., 2004). Finally, as an example, Lipkus et al. (2001) propose, among others, measures like the use of frequencies instead of percentages. Information presented as frequencies rather than probabilities carries more meaning and, as a result, greater weight in decisions.

\section{CLUSTER 2: PRESENTATION.}

Criterion 4. Coherence: CSR reports should present a unique internal consistency. Reports should be provided with a logic and harmonic structure (Zeller, 1987).

Criterion 5. Layout: Design presentation, distribution of texts, highlights, pictures, etc. within the page (Kim et al, 1999).

Criterion 6. Explanatory figures: The inclusion of figures as an intentional tool, using it to structure the explanation of the principal concepts or results (Walsh, 2010). 


\section{T. Gómez-Navarro, A. Baviera-Puig, G. García-Martínez/Corporate social responsibility reports based on communication}

\section{CLUSTER 3: DATA QUALITY.}

Criterion 7. Easiness to find particular data. Golob \& Bartlett (2007) discuss the importance of arranging the data so that every stakeholder can easily find the relevant data. Other studies have been found that agree on that (Sutantoputra, 2008).

Criterion 8. Relevance and Completeness: Relevance means readers find the information relevant to their interests (Schellens \& Menno, 1997). Besides, reports are more trusted as communication means when they are complete, i.e. when stakeholders find answers to all their questions (Schellens \& Menno, 1997). Coherently, inclusivity is also sought, i.e. to address all stakeholders (Sutantoputra, 2008).

Criterion 9. Accuracy and Sincerity: By sincerity authors mean telling the truth about a situation (Idowu \& Papsolomou, 2007; Du et al., 2010, Fassin, 2008). But also accuracy is needed avoiding to hide inconvenient data or facts (Kim et al, 1999).

\section{CLUSTER 4: RELIABILITY.}

Criterion 10. Data reliability: Presentation of clear references (Kim et al, 1999). Stating the source of empirical data, what kind of source and its reputation (Costanza et al., 1992). Verifiable, reports include data that can be verified, that can be checked or tested (Sutantoputra, 2008; Idowu \& Towler, 2004). Finally, also the inclusion of contact information and the communication channels (Kim et al, 1999).

Criterion 11. Stakeholders' participation: Reports are more trusted if included data partly (even mainly) come from stakeholders' demands, data, claims, etc. (Fassin, 2008)

Criterion 12. Auditing: Third part's examination of data, records or even procedures and estimations to check their accuracy (Tschopp, 2005).

\subsection{CSR reports}

In order to test the procedure a set of comparable CSR reports were selected. The CSR reports belong to all Spanish energy companies reporting by means of GRI: Abengoa Solar, Abengoa Bioenergy, Iberdrola, Gas Natural Fenosa, RepsolYPF, Enagas and Gamesa.

Comparability was defined according to the organization's economic activity (energy sector), its size (large), the publication date (year 2011), the organization's scope covered by the report (all activities), the region (all regions where the companies operate) and the reporting standard (GRI). This way the research focus mainly on the communication features as the companies have similar target stakeholders, communication demands, or CSR concerns. Also all CSR reports are GRI certified, as a way to prove the communication features of the reports depend more on the reporters' intentions than on the reporting method.

\subsection{The decision problem model}

According to the communication expert the correlation matrix is set as shown in Table 1. The network model is as shown in Figure 2.

Questionnaires were developed for stakeholders to assess the elements of the model i.e., the communication criteria and the CSR reports (Table 2). 
Table 1. Correlation Matrix.

\begin{tabular}{|c|c|c|c|c|c|c|c|c|c|c|c|c|c|c|c|c|c|c|c|c|}
\hline & & \multicolumn{3}{|c|}{$\begin{array}{l}\text { COMPRE- } \\
\text { HENSION }\end{array}$} & \multicolumn{3}{|c|}{$\begin{array}{l}\text { PRESEN- } \\
\text { TATION }\end{array}$} & \multicolumn{3}{|c|}{ QUALITY } & \multicolumn{3}{|c|}{$\begin{array}{l}\text { RELIABI- } \\
\text { LITY }\end{array}$} & \multicolumn{7}{|c|}{ ALTERNATIVES } \\
\hline & & 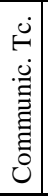 & 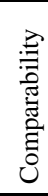 & $\begin{array}{l}\text { 奇 } \\
\frac{\mathrm{J}}{\mathrm{U}}\end{array}$ & 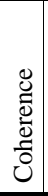 & 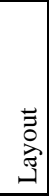 & 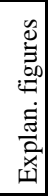 & 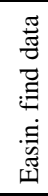 & 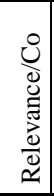 & 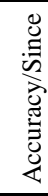 & 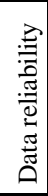 & 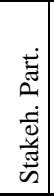 & 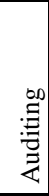 & 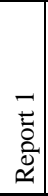 & 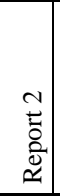 & $\begin{array}{l}m \\
\stackrel{0}{0} \\
\stackrel{0}{0} \\
\stackrel{4}{2}\end{array}$ & $\begin{array}{l}\stackrel{+}{ \pm} \\
\stackrel{0}{0} \\
\stackrel{0}{0} \\
\simeq\end{array}$ & $\begin{array}{l}n \\
\vdots \\
0 \\
00 \\
\simeq \\
\simeq\end{array}$ & 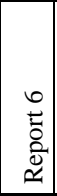 & 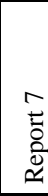 \\
\hline \multirow{3}{*}{$\begin{array}{l}\text { COMPREHEN- } \\
\text { SION }\end{array}$} & $\begin{array}{l}\text { Communication } \\
\text { technique }\end{array}$ & 0 & 0 & 1 & 0 & 1 & 1 & 0 & 0 & 1 & 0 & 0 & 0 & 1 & 1 & 1 & 1 & 1 & 1 & 1 \\
\hline & Comparability & 0 & 0 & 1 & 0 & 0 & 1 & 1 & 0 & 1 & 1 & 0 & 0 & 1 & 1 & 1 & 1 & 1 & 1 & 1 \\
\hline & Clarity & 0 & 0 & 0 & 0 & 0 & 0 & 1 & 0 & 1 & 0 & 0 & 0 & 1 & 1 & 1 & 1 & 1 & 1 & 1 \\
\hline \multirow{3}{*}{$\begin{array}{l}\text { PRESEN- } \\
\text { TATION }\end{array}$} & Coherence & 0 & 0 & 1 & 0 & 0 & 0 & 0 & 0 & 1 & 1 & 1 & 0 & 1 & 1 & 1 & 1 & 1 & 1 & 1 \\
\hline & Layout & 0 & 0 & 1 & 0 & 0 & 1 & 1 & 0 & 0 & 0 & 0 & 0 & 1 & 1 & 1 & 1 & 1 & 1 & 1 \\
\hline & Explanat. figures & 1 & 1 & 0 & 1 & 0 & 0 & 1 & 0 & 0 & 0 & 0 & 0 & 1 & 1 & 1 & 1 & 1 & 1 & 1 \\
\hline \multirow{3}{*}{ QUALITY } & Easiness find data & 0 & 1 & 1 & 0 & 0 & 0 & 0 & 0 & 0 & 1 & 0 & 0 & 1 & 1 & 1 & 1 & 1 & 1 & 1 \\
\hline & $\begin{array}{l}\text { Relevance/Complete } \\
\text { ness }\end{array}$ & 0 & 1 & 0 & 1 & 0 & 0 & 1 & 0 & 1 & 1 & 0 & 0 & 1 & 1 & 1 & 1 & 1 & 1 & 1 \\
\hline & Accuracy/Sincerity & 0 & 1 & 0 & 1 & 0 & 0 & 1 & 1 & 0 & 1 & 0 & 1 & 1 & 1 & 1 & 1 & 1 & 1 & 1 \\
\hline \multirow{3}{*}{ RELIABILITY } & Data reliability & 0 & 1 & 0 & 1 & 0 & 0 & 0 & 0 & $\overline{1}$ & 0 & 0 & 1 & 1 & 1 & 1 & 1 & 1 & 1 & 1 \\
\hline & Stakehs'. particip. & 0 & 0 & 0 & 1 & 0 & 0 & 0 & 0 & 1 & 1 & 0 & 0 & 1 & 1 & 1 & 1 & 1 & 1 & 1 \\
\hline & Auditing & 0 & 0 & 0 & 0 & 0 & 0 & 0 & 1 & 1 & 1 & 0 & 0 & 1 & 1 & 1 & 1 & 1 & 1 & 1 \\
\hline \multirow{7}{*}{ ALTERNATIVES } & Report 1 & 1 & 1 & 1 & 1 & 1 & 1 & 1 & 1 & 1 & 1 & 1 & 1 & 0 & 0 & 0 & 0 & 0 & 0 & 0 \\
\hline & Report 2 & 1 & 1 & 1 & 1 & 1 & 1 & 1 & 1 & 1 & 1 & 1 & 1 & 0 & 0 & 0 & 0 & 0 & 0 & 0 \\
\hline & Report 3 & 1 & 1 & 1 & 1 & 1 & 1 & 1 & 1 & 1 & 1 & 1 & 1 & 0 & 0 & 0 & 0 & 0 & 0 & 0 \\
\hline & Report 4 & 1 & 1 & 1 & 1 & 1 & 1 & 1 & 1 & 1 & 1 & 1 & 1 & 0 & 0 & 0 & 0 & 0 & 0 & 0 \\
\hline & Report 5 & 1 & 1 & 1 & 1 & 1 & 1 & 1 & 1 & 1 & 1 & 1 & 1 & 0 & 0 & 0 & 0 & 0 & 0 & 0 \\
\hline & Report 6 & 1 & 1 & 1 & 1 & 1 & 1 & 1 & 1 & 1 & 1 & 1 & 1 & 0 & 0 & 0 & 0 & 0 & 0 & 0 \\
\hline & Report 7 & 1 & 1 & 1 & 1 & 1 & 1 & 1 & 1 & 1 & 1 & 1 & 1 & 0 & 0 & 0 & 0 & 0 & 0 & 0 \\
\hline
\end{tabular}

Table 2. This is an example of a question asked to stakeholders.

In your opinion, what will influence more in the clarity of the CSR report of a given organization to change its comparability or to change its narrative Communication technique?

\section{Comparability}

Communication technique

\begin{tabular}{|c|c|c|}
\hline $\begin{array}{l}\text { Which is more } \\
\text { influential? }\end{array}$ & $\triangle$ Comparability $\square$ Com. Tec. & \\
\hline To what extent? & $\bigotimes$ Moderate & Very strong \\
\hline
\end{tabular}

The response means the responder believes the Communication technique employed for communicating particular concepts and data is moderately more influential in the clarity of this communication than providing comparisons with the competence or the evolution in time series of these particular concepts and data.

\section{Results and Discussion}

\subsection{Criteria and CSR reports weights (preferences)}

According to the stakeholders the Limit Supermatrix by stakeholder and, the Limit Supermatrix with aggregated results are shown in Table 3. Prioritizations of the different stakeholders were aggregated by means of the geometric mean according to Saaty's proposal (Saaty, 2001) Note: values have been normalized in two general groups: Alternatives (CSR reports) and Criteria (rest of the clusters). 


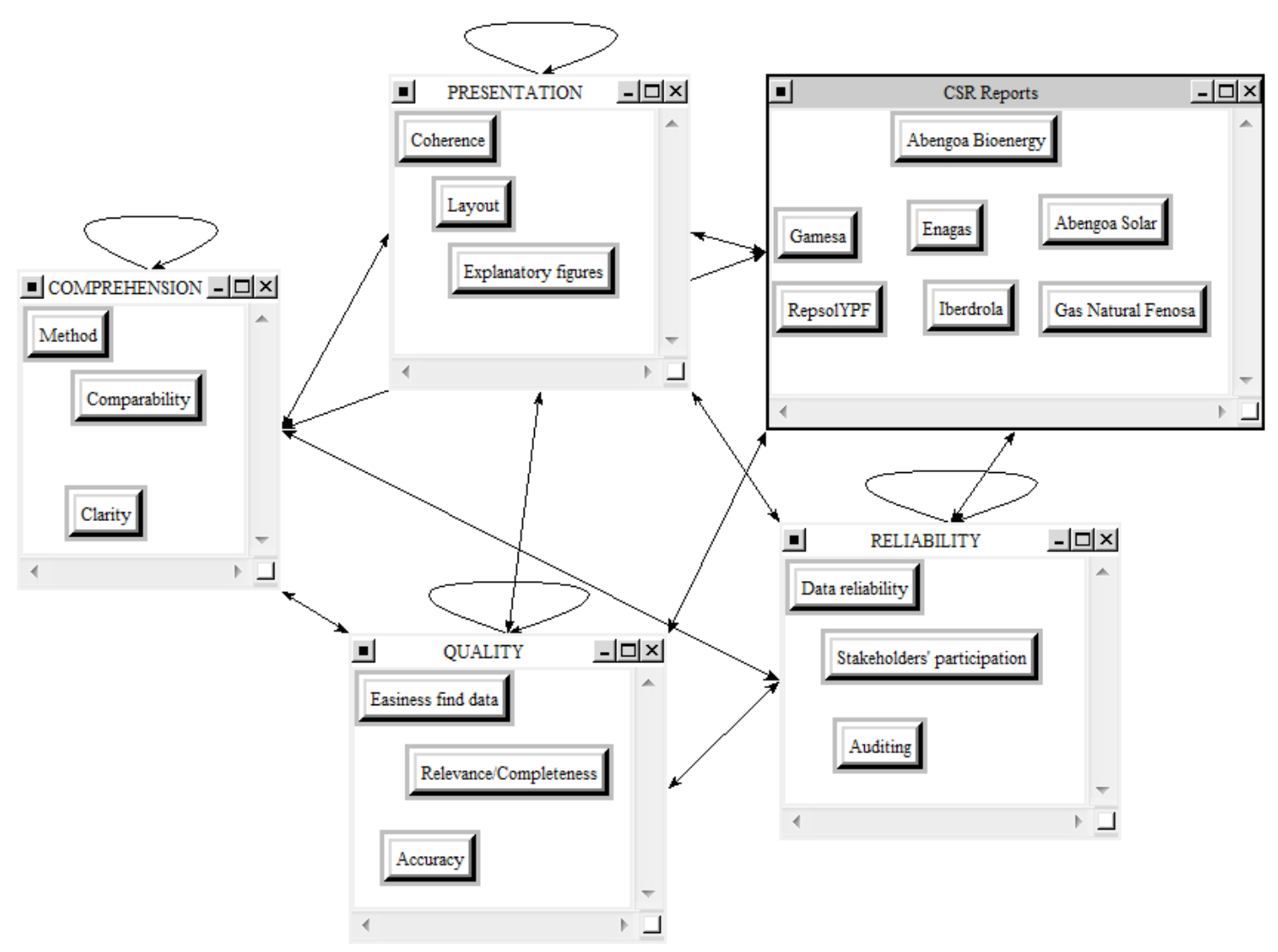

Figure 2. Network model of the problem.

Table 3. Aggregated Limit Supermatrix.

\begin{tabular}{|l|l|c|c|c|c|}
\hline \multirow{2}{*}{ CLUSTERS } & \multicolumn{1}{|c|}{ CRITERIA } & $\begin{array}{c}\text { Communication } \\
\text { expert }\end{array}$ & $\begin{array}{c}\text { Environmental } \\
\text { NGO expert }\end{array}$ & $\begin{array}{c}\text { Consumers } \\
\text { expert }\end{array}$ & Aggregated \\
\hline \multirow{5}{*}{ CSR REPORTS } & Report 1 & 0,137 & 0,134 & 0,101 & 0,125 \\
\cline { 2 - 6 } & Report 2 & 0,090 & 0,065 & 0,069 & 0,076 \\
\cline { 2 - 6 } & Report 3 & 0,148 & 0,185 & 0,140 & 0,160 \\
\cline { 2 - 6 } & Report 4 & 0,115 & 0,054 & 0,123 & 0,094 \\
\cline { 2 - 6 } & Report 5 & 0,205 & 0,262 & 0,261 & 0,244 \\
\cline { 2 - 6 } & Report 6 & 0,167 & 0,163 & 0,206 & 0,181 \\
\cline { 2 - 6 } & Report 7 & 0,138 & 0,137 & 0,101 & 0,127 \\
\hline \multirow{3}{*}{$\begin{array}{l}\text { COMPREHE- } \\
\text { NSION }\end{array}$} & Clarity & 0,061 & 0,026 & 0,044 & 0,043 \\
\cline { 2 - 6 } & Comparability & 0,089 & 0,076 & 0,077 & 0,083 \\
\cline { 2 - 6 } & Communic. Technique & 0,122 & 0,054 & 0,078 & 0,082 \\
\hline \multirow{3}{*}{$\begin{array}{l}\text { PRESENTA- } \\
\text { TION }\end{array}$} & Coherence & 0,079 & 0,095 & 0,085 & 0,088 \\
\cline { 2 - 6 } & Explanatory figures & 0,134 & 0,074 & 0,088 & 0,098 \\
\cline { 2 - 6 } & Layout & 0,078 & 0,045 & 0,060 & 0,061 \\
\hline \multirow{3}{*}{ QUALITY } & Accuracy/Sincerity & 0,104 & 0,140 & 0,158 & 0,135 \\
\cline { 2 - 6 } & Easiness find data & 0,085 & 0,058 & 0,063 & 0,069 \\
\hline
\end{tabular}




\begin{tabular}{|l|l|l|l|l|l|}
\hline & Relevance/Completeness & 0,092 & 0,087 & 0,115 & 0,100 \\
\hline \multirow{3}{*}{ RELIABILITY } & Auditing & 0,058 & 0,132 & 0,084 & 0,089 \\
\cline { 2 - 6 } & Data reliability & 0,062 & 0,153 & 0,102 & 0,101 \\
\cline { 2 - 6 } & Stakeholders' participation & 0,036 & 0,060 & 0,046 & 0,048 \\
\hline
\end{tabular}

Hence the communication criteria ranking is shown in Figure 3.
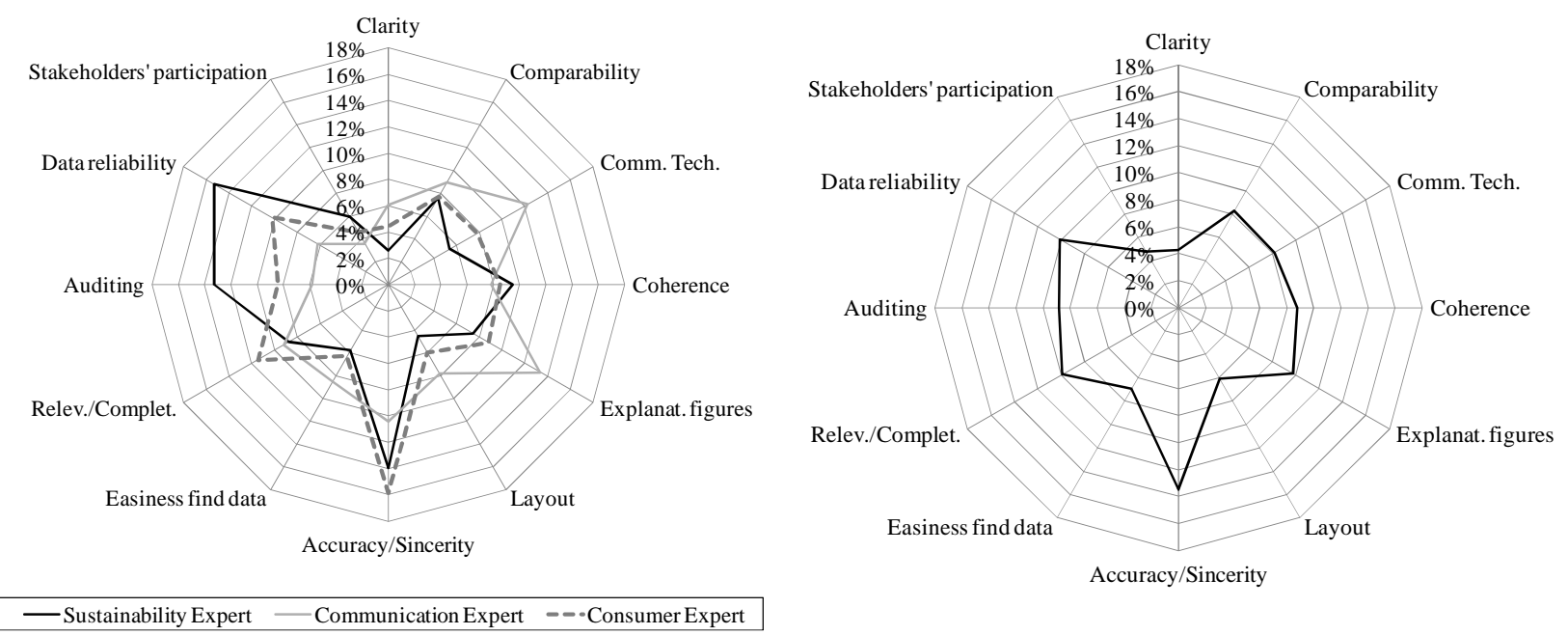

Figure 3. Criteria preference by stakeholder and aggregated.

And the results for the CSR report ranking Index are shown in Figure 3.

\subsection{Results by stakeholder}

As it can be seen in Table 3 and Figures 2 and 3, the communication expert prefers the criteria Explanatory figures and Communication technique to the rest. Interestingly, the least preferred criteria are Auditing and Stakehoders' participation. In fact, cluster Reliability is not much valued by the communication expert. Also, reports 5 and 6 are preferred to the rest, being reports 2 and 4 the least valued.

The environmental NGOs' expert prefers the criteria Data Reliability and Accuracy/Sincerity to the rest, while the least preferred criteria are Layout and Clarity. Contrary to the communication expert, the NGO expert clearly prefers the cluster Reliability to the rest and Comprehension is not much valued. Nevertheless, albeit paying attention to different criteria than the communication expert, reports 5 and 3 are preferred to the rest, being again reports 2 and 4 the least valued.

The consumers' expert prefers the criteria Accuracy/Sincerity and Relevance/Completeness to the rest, while the least preferred criteria are Clarity and Stakehoders' participation. The consumers' expert clearly prefers the cluster Quality to the rest. As for alternatives, reports 5 and 6 are again preferred to the rest, being reports 2,1 and 7 the least valued. 


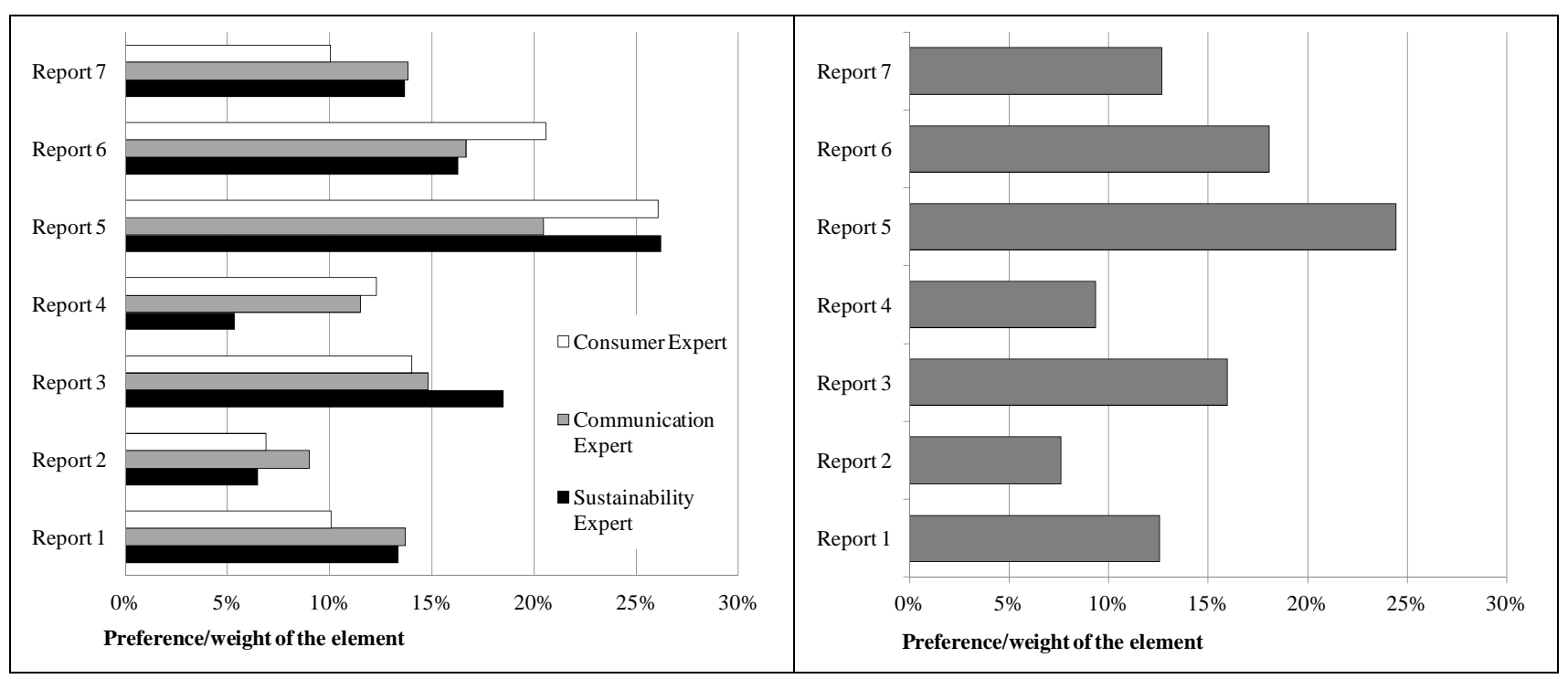

Figure 3. Alternatives preferences by stakeholder and aggregated.

\subsection{Results aggregated}

As it can be seen in Table 3 and Figures 2 and 3, the aggregation of the preferences by means of the geometric mean give as a result the criteria Accuracy/Sincerity, Data reliability and Relevance/Completeness being preferred to the rest. The least preferred criteria, in average, are Clarity and Stakehoders' participation. Cluster Quality is the most valued. About alternatives, reports 5 and 6 are preferred to the rest, being reports 2 and 4 the least valued. This results are quite clear and a classification can be made in four levels: Excellent (no report), Good communication (reports 5 and 6), Fair communication (reports 1, 3 and 7) and Poor communication (reports 2 and 4).

\section{Conclusions}

Results for the case study show even in GRI certified reports publicity objectives overcome CSR objectives. Therefore, among others consequences, stakeholders tend to not to trust them, relevant information is difficult to find and some of the target stakeholders do not get aware of the information at their disposal.

A methodology based on communication criteria and the ANP method has been presented ranking the reports according to a communicaiton Index. This Index ranks the alternatives by comparing them to each other, i.e., it gives relative results. Therefore, the index can be used for benchmarking but it should not be used as an absolute assessment index. Its strength relies on the procedure. ANP has allowed determining the criteria, the relationship among criteria and their weighting.

\section{REFERENCES}

COM, Commission of the European Communities. (2001). Promoting a European Framework for Corporate Social Responsibilities, COM (2001) 366 final, Brussels.

Costanza, R., Funtowicz, S. O. \& Ravetz, J. R. (1992). Assessing and communicating data quality in policy relevant research. Environmental Management, 16, 121-131. 
Coupland, C., (2006) Corporate social and environmental responsibility in web-based reports: Currency in the banking sector?, Critical Perspectives on Accounting, 17, 865-881

Du, S., Bhattacharya, C.B., Sen, S., (2010) Maximizing Business Returns to Corporate Social Responsibility (CSR): The Role of CSR Communication, International Journal of Management Reviews.

Fassin, Y., (2008) SMEs and the fallacy of formalising CSR, Business Ethics: A European Review, 17-4

Gibbs, D.A., Sangl, J.A., \& Burrus, B. (1996). Consumer perspectives on information needs for health plan choice. Health Care Financing Review, 18, 55-73.

Golob, U., Bartlett J.L., (2006) Communicating about corporate social responsibility: A comparative study of CSR reporting in Australia and Slovenia, Public Relations Review, 33, 1-9

Graesser, A.C., McNamara, D.S., Louwerse, M., \& Cai, Z. (2004). Coh-Metrix: Analysis of text on cohesion and language. Behavior Research Methods, Instruments, \& Computers, 36, 193-202.

Hibbard, J.H., Stockard, J., \& Tusler, M. (2002). Does making hospital performance public increase quality improvement efforts? An evaluation using an experimental design in the state of Wisconsin. Presented at Academic Health Services Research and Health Policy Annual Research Meeting, Washington, DC.

Idowu, S.O., Papasolomou, I., (2007) Are the corporate social responsibility matters based on good intentions or false pretences? An empirical study of the motivations behind the issuing of CSR reports by UK companies, Corporate Governance, 7-2, 136-147

Idowu, S.O., Towler, B.A., (2004) A comparative study of the contents of corporate social responsibility reports of UK companies. Management of Environmental Quality: An Internat. Journal, 15-4, 420-437

Jewett, J.J., \& Hibbard, J.H. (1996). Comprehension of quality care indicators: differences among privately insured, publicly insured, and uninsured. Health Care Financing Review, 18(1), 75-94.

Kim, P., Eng, T.R., Deering, M.J., \& Maxfield, A. (1999). Published criteria for evaluating health related Web sites: Review. British Medical Journal, 318, 647-649.

Knox, S., Maklan, S., French, P., (2005) Corporate Social Responsibility: Exploring Stakeholder Relationships and Programme Reporting across Leading FTSE Companies, Journal of Business Ethics, $61,7-28$

Lipkus, I.M., Samsa, G., \& Rimer, B.K. (2001). Decision psychology and risk perception general performance on a numeracy scale among highly educated samples. Medical Decision Making, 21, 37-44.

Saaty, T., (2001), The Analytic Network Process. Decision Making with interdependence and feedback. RWS Publications. Pittsburgh

Sanfey, A., \& Hastie, R. (1998). Does evidence presentation format affect judgment? Psychological Science, 9, 99-103.

Schellens, P.J., \& De Jong, M. (1997). Revision of public information brochures on the basis of reader feedback. Journal of Business and Technical Communication, 11(4), 483-501.

Sutantoputra, A.W., (2009) Social disclosure rating system for assessing firms' CSR reports, Corporate Communications: An International Journal,14-1, 34-48

Tschopp, D.J., (2005) Corporate Social Responsibility: A Comparison Between the United States and the European Union, Corp. Soc. Responsib. Environ. Mgmt. 12, 55-59

Walsh, L. (2010). The Common Topoi of STEM Discourse: An Apologia and Methodological Proposal, With Pilot Survey. Written Communication, 27(1), 120-156.

Zeller, N. (1987). A rhetoric for naturalistic inquiry. Unpublished doctoral dissertation: Indiana University. 